\title{
Bronchogenic cyst associated with pericardial defect: Case report and review of the literature
}

\author{
Andrea Imperatori ${ }^{1}$, Nicola Rotolo ${ }^{1}$, Elisa Nardecchia', Giovanni Mariscalco ${ }^{2}$, Marco Spagnoletti ${ }^{1}$ and \\ Lorenzo Dominioni ${ }^{1 *}$
}

\begin{abstract}
Partial defect of the pericardium combined with bronchogenic cyst is a very rare congenital anomaly. We describe the case of a 32-year-old man with a partial defect of the left pericardium and a bronchogenic cyst arising from the border of the pericardial defect. The cyst was successfully resected with the harmonic scalpel by three-port videothoracoscopic approach.
\end{abstract}

Keywords: Bronchogenic cyst, pericardial defect, video-thoracoscopy, harmonic scalpel

\section{Background}

Mediastinal bronchogenic cysts (BC) are uncommon pathologic entities of congenital origin, representing $12 \%$ to $18 \%$ of all primary mediastinal masses [1-3]. Although $\mathrm{BC}$ are often asymptomatic, they can be complicated by infection, compression of the trachea or superior vena cava, intracystic hemorrhage, rupture, hemoptysis, and malignant changes [4-7].

$\mathrm{BC}$ have been reported to be also associated with other congenital malformations, including cardiac and pericardial anomalies [8-21]. Partial or total pericardial defect (PD) associated with $\mathrm{BC}$ is a very rare malformation, of which only 19 cases have been reported in the literature.

We present here a case of mediastinal $\mathrm{BC}$ associated with partial PD, successfully treated by a video-assisted thoracoscopic surgery (VATS). We also review the literature concerning the clinical presentation and management of $\mathrm{BC}$ associated with PD.

\section{Case presentation}

A 32-year-old man was admitted to our department complaining of left chest pain and cough. Chest radiography showed a large round opacity $(10 \times 10 \mathrm{~cm})$ of the left hilum (Figure 1). The electrocardiogram was normal. Computed tomography (CT) scan demonstrated

\footnotetext{
* Correspondence: Iorenzo.dominioni@uninsubria.it

'Department of Surgical Sciences, Thoracic Surgery Unit, Varese University

Hospital, University of Insubria, Varese, Italy

Full list of author information is available at the end of the article
}

a large cystic mass arising from the pericardium, adjacent to the left pulmonary pericardial sinus (Figure 2); no other abnormalities were observed.

Resection of the cystic mass was effected by VATS, with three-port approach on the left side. At thoracoscopy a left upper pericardial defect $(3 \times 4 \mathrm{~cm})$, ovalshaped, was found. A large cyst was identified, arising from the upper border of the PD. The cyst was adherent to the left main pulmonary artery and to the visceral pleura of the left lung upper lobe (Figure 3). After needle aspiration of part of the dense fluid content of the cyst, the latter was dissected from adhesions to the lung and to the upper border of the pericardial defect, using the harmonic scalpel. The cyst was radically resected with minimal blood loss and without complications. The left atrial appendage was partly bulging from the pericardial defect, but without herniation. Therefore the defect was left untreated. Pathology of the resected specimen revealed a bronchogenic cyst (Figure 4). The postoperative course was uneventful. Cardiac function was monitored postoperatively by transthoracic echocardiography, which demonstrated no cardiac herniation, and the patient was discharged on the 5th postoperative day. At 18-month follow-up the patient was asymptomatic; cardiac magnetic resonance imaging and transthoracic echocardiography demonstrated no cardiac herniation nor functional deficiency, also when the patient was examined in the left lateral decubitus position [22].
C Biomed Central 


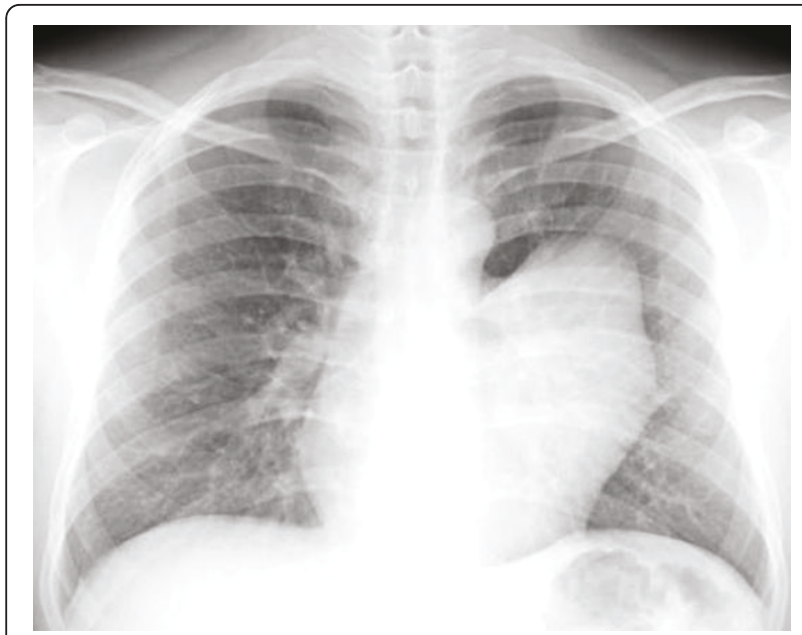

Figure 1 Chest $X$-rays showing mediastinal mass. Chest $X$-ray showing a large round opacity of the left hilum.

\section{Discussion}

$\mathrm{BC}$ are the most common cystic lesions of the mediastinum and account for $18 \%$ of all primitive mediastinal masses. The prevalence of $\mathrm{BC}$ is difficult to ascertain, because they frequently are asymptomatic [5,23-26]. While most $\mathrm{BC}$ are located in the mediastinum, $15 \%$ to $30 \%$ of them are found within the lung parenchyma; in the latter case the lower lobes are most commonly involved [1-3]. Atypical locations of $\mathrm{BC}$ are also

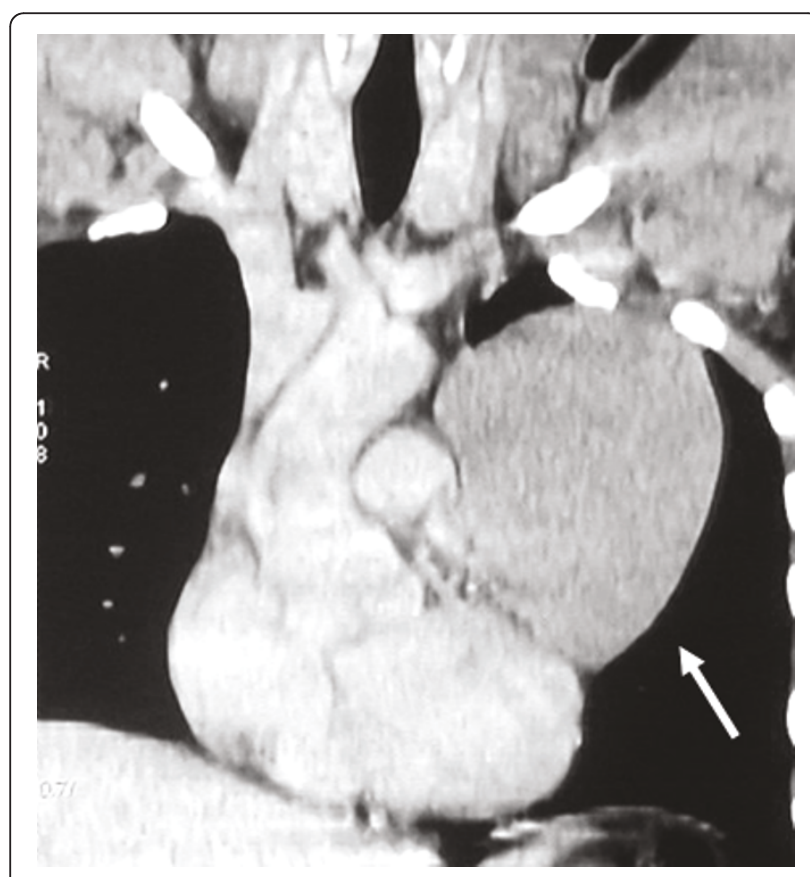

Figure 2 CT scan showing cystic mass. CT scans showing a well circumscribed cystic mass $(10 \times 10 \mathrm{~cm})$ adjacent to the left pulmonary artery (arrow)

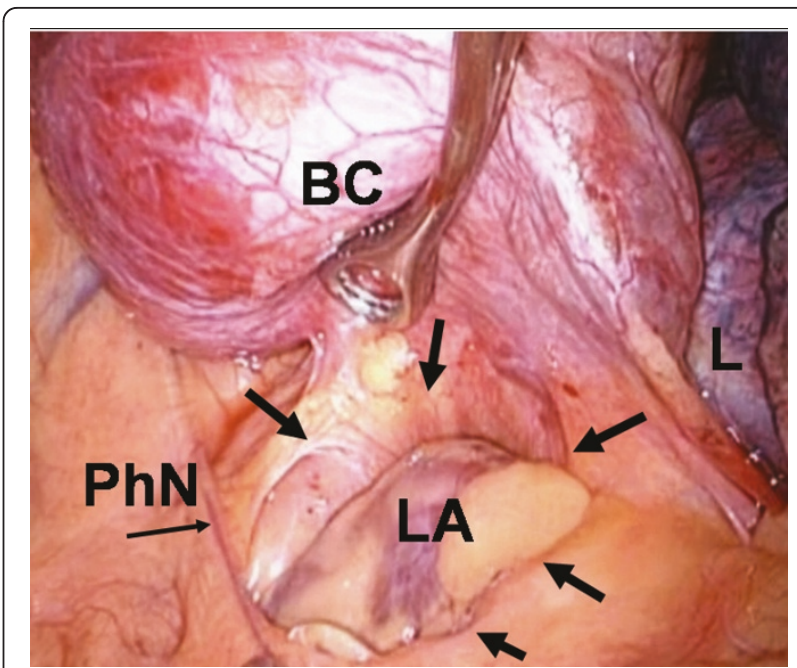

Figure 3 Intraoperative video-thoracoscopic detail Intraoperative view showing bronchogenic cyst (BC), left atrial appendage (LA) visible through the pericardial defect (arrows), phrenic nerve $(\mathrm{PhN})$, left upper lobe of the lung $(\mathrm{L})$.

reported, including the neck, the spinal dura mater and the diaphragmatic region [1-3]. BC are congenital malformations arising from the primitive foregut with an abnormal division of the tracheobronchial tree; the stage of embryonic development determines the mediastinal location [26]. In case of early separation from the main tracheobronchial tree, $\mathrm{BC}$ are located in the mediastinum close to the trachea, carina, main bronchi or esophagus; histologically these entities present ciliated epithelium derived from either the respiratory or the alimentary tract. When the separation occurs late, BC involve the lung parenchyma and the cysts present a

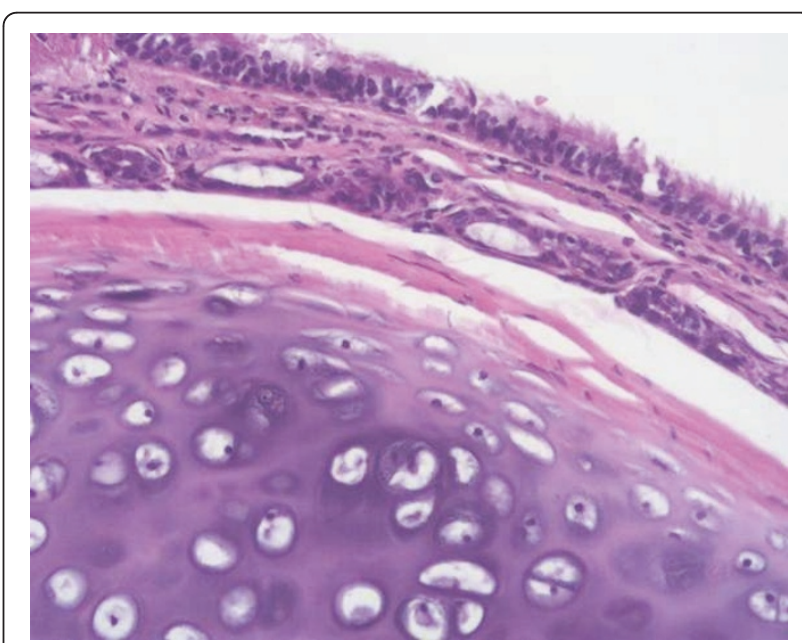

Figure 4 Histology of cystic mass. Histological section of the bronchogenic cyst, showing ciliated epithelium and cartilages (HE stain, 20X) 
lined respiratory epithelium [5,27]. BC are most frequently unilocular; their fluid content may be clear, or dense and yellow, or hemorrhagic, or mixed with air in case of intrapulmonary location of the cyst.

No clinical presentation is specifically suggestive of $\mathrm{BC}$ because these lesions are frequently asymptomatic, their diagnosis being incidental [6,23]. Chest pain, cough, dyspnea, and dysphagia are reported as possible clinical manifestations of $\mathrm{BC}$, arising from compression of the esophagus and/or major airways [4-7,23]. In the case we are reporting, the patient was symptomatic for cough and chest pain; the preoperative diagnosis of $\mathrm{BC}$ was made by chest radiography and CT scan.

Complete surgical excision is the treatment of $\mathrm{BC}$ generally accepted, because these lesions do not spontaneously regress and can enlarge or become infected. Several surgical techniques have been described $[5,23-26,28]$. Drainage of a compressive cyst is a temporary palliative procedure, generally reserved to inoperable patients, to the management of recurrences and of severe compression [5,29]. Surgical approaches include thoracotomy and VATS [5,23-26]. In the last decade VATS has emerged for the treatment of BC in absence of severe adhesions to surrounding mediastinal organs $[29,30]$. In the present case the mediastinal BC was resected by thoracoscopic approach, using the harmonic scalpel, a technique that has become available in recent years and proved to be safe and effective [31]. Harmonic scalpel confers some advantages over conventional methods of dissection, such as electric cautery, in VATS procedures. It reduces blood loss, duration of drainage and length of the VATS procedure with a comparable cost as compared to electric cautery. Similar advantages of harmonic scalpel have been observed in other surgical fields, such as thyroid surgery [32], video-assisted thoracoscopic thymic resection [33] and vascular surgery [34].

Various congenital anomalies of the heart, lung, chest wall and diaphragm have been reported to be associated with BC. PD, patent ductus arteriosus, atrial septal defect, tetralogy of Fallot, mitral stenosis, pulmonary sequestration and diaphragmatic hernia have been encountered in association with BC [4,5]. During development of the pleuropericardial fold, pericardial defects and lung anomalies such as bronchogenic cyst may occur together [15]; this event is unlikely to be coincidental. In the present case, a partial PD was incidentally discovered during surgery for resection of $\mathrm{BC}$. Congenital PD is a rare anomaly presenting as a complete or partial absence of the pericardium. Partial absence more commonly occurs on the left side $(70 \%)$ than on the right $(17 \%)$ or in the inferior portion of the pericardium [22]. The prevalence of PD is likely underestimated, because the symptoms are absent or scarce and the diagnostic criteria are poorly known [35]. It should be emphasized that the intact pericardium over the left atrial appendage is very thin and may not be identified even in normal people; thus, a partial left PD is nearly impossible to be recognized by routine CT scan, unless the atrial appendage is frankly bulging from the defect [22].

Usually patients with PD are asymptomatic and the diagnosis is incidental during thoracic surgery for unrelated conditions, as in our case.

Atypical angina symptoms or dyspnea are possible unspecific manifestations [36]. Although small defects occasionally induce serious or even lethal complications due to the incarceration of cardiac tissue, large or total left-sided PDs are usually considered benign and deserve no treatment. Surgical repair is required in case of large cardiac herniation and imminent strangulation [36].

We reviewed the literature pertinent to $\mathrm{BC}$ associated to PD, and found only 17 published cases of that combined congenital malformation. Table 1 summarizes the features of the 14 cases for which complete information were available (3 cases were not reported in English language) and shows that all patients had symptoms due to $\mathrm{BC}$, while the $\mathrm{PD}$ was incidentally discovered during surgery performed to excise the cyst; left partial PD predominated, and in only 3 cases a direct suture of the defect was required.

To our knowledge, the case of $\mathrm{BC}$ associated to PD presented here is the first described that was treated by VATS approach, using the harmonic scalpel for resecting the cyst. The decision to close the PD can only be made on an individual basis, after evaluation of the specific anatomical alterations. In our case we did not close the partial PD because the left atrial appendage was adherent with the inner aspect of the pericardium and did not herniate; that decision proved to be appropriate, because at 18-month follow-up the transthoracic echocardiography confirmed no cardiac herniation nor functional deficiency.

In conclusion, in the case presented the VATS approach to resect the $\mathrm{BC}$ with the harmonic scalpel and the decision to leave the PD open proved to be safe, effective and minimally invasive.

\section{Consent}

Written informed consent was obtained from the patient for publication of this case report and any accompanying images. A copy of the written consent is available for review by the Editor in Chief of this journal. 
Table 1 Cases of bronchogenic cyst associated with pericardial defect published in the English language literature

\begin{tabular}{|c|c|c|c|c|c|c|c|c|c|}
\hline Author [ref] & Year & Case $n .^{*}$ & Age/Sex & $\begin{array}{l}\text { Size } \\
(\mathrm{cm})\end{array}$ & Location & Symptoms & $\begin{array}{l}\text { Surgical } \\
\text { Treatment } †\end{array}$ & $\begin{array}{l}\text { Pericardial defect } \\
\text { Location/Extension }(\mathrm{cm})\end{array}$ & $\begin{array}{l}\text { Other } \\
\text { congenital } \\
\text { anomalies }\end{array}$ \\
\hline $\begin{array}{l}\text { Rusby and Sellors } \\
{[12]}\end{array}$ & 1945 & 1 & $19, F$ & 6 & $\begin{array}{l}\text { L upper } \\
\text { lobe }\end{array}$ & Chest pain & Excision & L, Partial & none \\
\hline \multirow[t]{5}{*}{ Jones P. [13] } & 1955 & 2 & $9, \mathrm{M}$ & - & L hilum & Bronchitis & Excision & L, Partial $3 \times 2$ & none \\
\hline & & 3 & $22, \mathrm{M}$ & - & $\begin{array}{l}\text { L upper } \\
\text { lobe }\end{array}$ & Asymptomatic & Lobectomy & L, Partial (extensive) & none \\
\hline & & 4 & $21, M$ & - & $\mathrm{R}$ lung apex & Asymptomatic & Lobectomy & R, Partial $4 \times 2.5$ & none \\
\hline & & 5 & $22, F$ & - & $\begin{array}{l}\text { L upper } \\
\text { lobe }\end{array}$ & Asymptomatic & Excision & L, Partial, $2.5 \times 2.5$ & none \\
\hline & & 6 & $9, M$ & $\begin{array}{l}10 \times \\
6\end{array}$ & $\mathrm{R}$ lung apex & Infections & - & R, Partial & $\begin{array}{l}\text { Double BC, } \\
\text { vascular }\end{array}$ \\
\hline Warner et al. [14] & 1958 & 7 & $71 / 2, M$ & $2 \times 2$ & $\begin{array}{l}\text { L upper } \\
\text { lobe }\end{array}$ & Asymptomatic & Excision & Complete & Pleural defect \\
\hline Hamilton LC. [15] & 1961 & 8 & $10, M$ & - & L lower lobe & Pneumonia & Excision & L, Partial & Pleural defect \\
\hline Mukerjee S. [16] & 1964 & 9 & $24, F$ & - & $\begin{array}{l}\text { L upper } \\
\text { lobe }\end{array}$ & Chest pain & Excision & L, Partial & Pleural defect \\
\hline Kwak et al. [17] & 1971 & 10 & $15, F$ & $\begin{array}{l}7.5 \times \\
5 \times \\
3.6\end{array}$ & L hilum & Asymptomatic & $\begin{array}{l}\text { Excision + } \\
\text { PDS }\end{array}$ & L, Partial $2 \times 2$ & none \\
\hline Kassner et al. [18] & 1975 & 11 & $2, F$ & $6 \times 6$ & $\begin{array}{l}\text { L upper } \\
\text { lobe }\end{array}$ & Asymptomatic & $\begin{array}{l}\text { Excision + } \\
\text { PDS }\end{array}$ & L, Partial $2 \times 2$ & Hip dislocation \\
\hline Victor and Daniel [19] & 1981 & 12 & $14, M$ & $5 \times 4$ & $\begin{array}{l}\text { R upper } \\
\text { lobe }\end{array}$ & $\begin{array}{l}\text { Dyspnea, } \\
\text { dysphagia }\end{array}$ & $\begin{array}{l}\text { Excision + } \\
\text { PDS }\end{array}$ & R, Partial & none \\
\hline Eom et al. [20] & 2007 & 13 & $18, M$ & $\begin{array}{l}8 \times 7 \\
\times 4.5\end{array}$ & mediastinum & $\begin{array}{l}\text { Cough, } \\
\text { dyspnea }\end{array}$ & Excision & L, Partial & none \\
\hline Özpolat et al. [21] & 2009 & 14 & $15, M$ & - & $\begin{array}{l}\text { L upper } \\
\text { lobe }\end{array}$ & $\begin{array}{l}\text { Chest pain, } \\
\text { dysphagia, } \\
\text { dyspnea }\end{array}$ & Excision & L, Partial & $\begin{array}{l}\text { ASD, MVP, } \\
\text { hypospadias }\end{array}$ \\
\hline Present case & 2010 & 15 & $32, M$ & $\begin{array}{l}10 \times \\
10\end{array}$ & L hilum & $\begin{array}{l}\text { Chest pain, } \\
\text { cough }\end{array}$ & $\begin{array}{l}\text { Excision } \\
\text { (VATS) }\end{array}$ & L, Partial & none \\
\hline
\end{tabular}

ASD, atrial septal defect; BC, bronchogenic cyst; F, female; L, left; R, right; M, male; MVP, mitral valve prolapse; PDS, pericardial defect sutured; VATS, videoassisted thoracoscopic surgery.

* Details of three other cases were not listed because publications were not in English language [ref. \# [23-25]].

† Surgical approach to the cysts was accomplished in all case by left or right thoracotomy.

\section{Abbreviations}

BC: bronchogenic cysts; PD: pericardial defect; VATS: video-assisted thoracoscopic surgery; CT: Computed tomography.

\section{Author details}

${ }^{1}$ Department of Surgical Sciences, Thoracic Surgery Unit, Varese University Hospital, University of Insubria, Varese, Italy. ${ }^{2}$ Department of Surgical Sciences, Cardiac Surgery Unit, Varese University Hospital, University of Insubria, Varese, Italy.

\section{Authors' contributions}

All Authors: 1. have made substantial contributions to conception and design, or acquisition of data, or analysis and interpretation of data; 2 . have been involved in drafting the manuscript or revising it critically for important intellectual content; 3 . have given final approval of the version to be published.

\section{Competing interests}

The authors declare that they have no competing interests.

Received: 16 February 2011 Accepted: 20 June 2011 Published: 20 June 2011

\section{References}

1. St-Georges R, Deslauriers J, Duranceau A, Vaillancourt R, Deschamps C, Beauchamp G, Page A, Brisson J: Clinical spectrum of bronchogenic cysts of the mediastinum and lung in the adult. Ann Thorac Surg 1991, 52:6-13.
2. Di Lorenzo M, Collin PP, Vaillancourt R, Duranceau A: Bronchogenic cysts. J Pediatr Surg 1989, 24:988-91.

3. Suen HC, Mathisen DJ, Grillo HC, LeBlanc J, McLoud TC, Moncure AC, Hilgenberg AD: Surgical management and radiological characteristics of bronchogenic cysts. Ann Thorac Surg 1993, 55:476-81.

4. Ahn C, Hosier DM, Vasko JS: Congenital pericardial defect with herniation of the left atrial appendage. Ann Thorac Surg 1969, 7:369-84.

5. Ribet ME, Copin MC, Gosselin BH: Bronchogenic cysts of the lung. Ann Thorac Surg 1996, 61:1636-40.

6. Patel SR, Meeker DP, Biscotti CV, Kirby TJ, Rice TW: Presentation and management of bronchogenic cysts in the adult. Chest 1994, 106:79-85.

7. Mondello B, Lentini S, Familiari D, Barresi P, Monaco F, Sibilio M, La Rocca A, Micali V, Acri IE, Barone M, Monaco M: Thoracoscopic resection of a paraaortic bronchogenic cyst. J Cardiothorac Surg 2010, 5:82-5.

8. Rusby N, Sellors T: Conegenital deficiency of the pericardium. Report of a case. Br J Surg 1945, 32:357-64.

9. Jones P: Developmental defects in the lungs. Thorax 1955, 10:205-13.

10. Warner $\mathrm{CL}$, Britt RL, Riley HD Jr: Bronchopulmonary sequestration in infancy and childhood. J Pediatr 1958, 53:521-8.

11. Hamilton LC: Congenital deficiency of the pericardium. A case report of complete absence of the left pericardium. Radiology 1961, 77:984-6.

12. Mukerjee S: Congenital Partial Left Pericardial Defect With $A$ Bronchogenic Cyst. Thorax 1964, 19:176-9.

13. Kwak DL, Stork WJ, Greenberg SD: Partial defect of the pericardium associated with a bronchogenic cyst. Radiology 1971, 101:287-8. 
14. Kassner EG, Rosen Y, Klotz DH Jr: Mediastinal esophageal duplication cyst associated with a partial pericardial defect. Pediatr Radiol 1975, 4:53-6.

15. Victor S, D Dl: Congenital partial pericardial defect on the right side associated with a bronchogenic cyst. A case report. Indian Heart J 1981, 33:34-6

16. Eom DW, Kang GH, Kim JW, Ryu DS: Unusual bronchopulmonary foregut malformation associated with pericardial defect: bronchogenic cyst communicating with tubular esophageal duplication. J Korean Med Sci 2007, 22:564-7.

17. Ozpolat B, Dogan OV: Absence of pericardium in combination with bronchogenic cyst, atrial septal defect, mitral valve prolapsus and hypospadias. Anadolu Kardiyol Derg 2009, 9:E16-7.

18. Takizawa H, Ishikura H, Kimura S, Yuasa Y, Okitsu H, Sakata A: Giant pulmonary cyst associated with congenital pericardial defect. Gen Thorac Cardiovasc Surg 2007, 55:65-8

19. Horiide R, Ishikawa N, Ogata K: [Case of mediastinal bronchogenic cyst associated with partial pericardial defect and cured by excision.]. Kyobu Geka 1963, 16:46-50.

20. Marushkin AV, Troshin AP, Malkin DM, Lelechenko VI: [Rare case of association of mediastinal bronchogenic cyst with pericardial defect]. Vestn Khir Im I I Grek 1978, 120:85-6.

21. Voronov AA, Gavrilov SG: [Congenital absence of the pericardium in combination with bronchogenic cyst of the left lung.]. Grudn Khir 1962, 4:78-9.

22. Rajia P, Kanne JP: Computed tomography of the pericardium and pericardial disease. J Cardiovasc Comput Tomogr 2010, 4:3-18.

23. Takeda S, Miyoshi S, Minami M, Ohta M, Masaoka A, Matsuda H: Clinical spectrum of mediastinal cysts. Chest 2003, 124:125-32.

24. Sarper A, Ayten A, Golbasi I, Demircan A, Isin E: Bronchogenic cyst. Tex Heart Inst J 2003, 30:105-8.

25. Kanemitsu $Y$, Nakayama $H$, Asamura $H$, Kondo $H$, Tsuchiya $R$, Naruke $T$ : Clinical features and management of bronchogenic cysts: report of 17 cases. Surg Today 1999, 29:1201-5.

26. Aktogu S, Yuncu G, Halilcolar H, Ermete S, Buduneli T: Bronchogenic cysts: clinicopathological presentation and treatment. Eur Respir J 1996, 9:2017-21

27. Takeda S, Miyoshi S, Inoue M, Omori K, Okumura M, Yoon HE, Minami M, Matsuda $\mathrm{H}$ : Clinical spectrum of congenital cystic disease of the lung in children. Eur J Cardiothorac Surg 1999, 15:11-7.

28. Rapado F, Bennett JD, Stringfellow JM: Bronchogenic cyst: an unusual cause of lump in the neck. J Laryngol Otol 1998, 112:893-4.

29. Granato F, Luzzi L, Voltolini L, Gotti G: Video-assisted mediastinoscopic resection of two bronchogenic cysts: a novel approach. Interact Cardiovasc Thorac Surg 2010, 11:335-6

30. Granato F, Voltolini L, Ghiribelli C, Luzzi L, Tenconi S, Gotti G: Surgery for bronchogenic cysts: always easy? Asian Cardiovasc Thorac Ann 2009, 17:467-71

31. Lang-Lazdunski L, Pilling J: Videothoracoscopic excision of mediastinal tumors and cyst using the harmonic scalpel. Thorac Cardiovasc Surg 2008, 56:278-82.

32. Miccoli P, Materazzi G, Fregoli L, Panicucci E, Kunz-Martinez W, Berti P: Modified lateral neck lymphadenectomy: prospective randomized study comparing harmonic scalpel with clamp- and-tie technique. Otolaryngol Head Neck Surg 2009, 140:61-4

33. Soon $J L$, Agasthian T: Harmonic scalpel in video-assisted thoracoscopic thymic resections. Asian Cardiovasc Thorac Ann 2008, 16:366-9.

34. Canosa C, Nasso G, De Filippo CM, Modugno P, Spatuzza P, Calvo E, Testa N, Alessandrini F: Open clip-free radial artery harvesting with the harmonic shears. J Card Surg 2007, 22:139-41.

35. Garnier F, Eicher JC, Philip JL, Lalande A, Bieber H, Voute MF, Brenot R, Brunotte F, Wolf JE: Congenital complete absence of the left pericardium: a rare cause of chest pain or pseudo-right heart overload. Clin Cardiol 2010, 33:E52-7.

36. Bruning EG: Congenital defect of the pericardium. J Clin Pathol 1962, 15:133-5.

doi:10.1186/1749-8090-6-85

Cite this article as: Imperatori et al.: Bronchogenic cyst associated with pericardial defect: Case report and review of the literature. Journal of Cardiothoracic Surgery 2011 6:85.

\section{Submit your next manuscript to BioMed Central and take full advantage of:}

- Convenient online submission

- Thorough peer review

- No space constraints or color figure charges

- Immediate publication on acceptance

- Inclusion in PubMed, CAS, Scopus and Google Scholar

- Research which is freely available for redistribution 